REFERENCES:

[1] Tanaka H, Tanaka K, et al. Analysis of pregnancies in women with Takayasu arteritis: Complication of Takayasu arteritis involving obstetric or cardiovascular events. J Obstet Gynaecol Res. 2014 Sep;40(9):2031-6.

[2] Gudbrandsson B, Wallenius M, et al. Takayasu arteritis and pregnancy; a population based study on outcome and mother child related concerns. Arthritis Care Res (Hoboken). 2017 Sep;69(9):1384-1390.

[3] Assad AP, da Silva TF, et al. Maternal and Neonatal Outcomes in 89 Patients with Takayasu Arteritis (TA): Comparison Before and After the TA Diagnosis. J Rheumatol. 2015 Oct;42(10):1861-4.

[4] Comarmond C, Mirault T, et al. Takayasu Arteritis and Pregnancy. Arthritis Rheumatol. 2015 Dec;67(12):3262-9.

Disclosure of Interest: None declared

DOI: 10.1136/annrheumdis-2018-eular.7107

\section{AB0668 TREATMENT OF THROMBOTIC EVENTS IN BEHÇET DISEASE: A SYSTEMATIC LITERATURE REVIEW}

I. Janta, R.D. Gonzalez Benitez, B. Serrano Benavente, I. Monteagudo Saez. Rheumatology, Gregorio Marañón General Hospital, Madrid, Spain

Background: Behçet's disease (BD) is a systemic disease which etiopathogenesis is largely unknown. It is characterised by a wide variety of clinical manifestations. Venous disorder is a serious manifestation being potentially lifethreatening. There is little evidence on the management of the venous complications in BD.

Objectives: To perform a systematic literature review on the treatment used in venous thrombotic events in BD.

Methods: The objective was reformulated according to the PICO approach. Several synonyms for the main components (i.e. Behçet, thrombosis, treatment) were used. Search limits were applied for humans. The literature search was performed in Medline and Embase from databases inception to 1st November 2017. Only articles in English and Latin languages were retained. We excluded abstracts, reviews and letters. From the selected studies, data about the venous involvement and treatments were retired using a predefined data collection form.

Abstract AB0668 - Table 1

\begin{tabular}{lc}
\hline Treatment & $\mathbf{N}^{\circ}$ articles $(\%)$ \\
\hline Anticoagulant & $22(78.6)$ \\
Antiplatelet & $9(33.3)$ \\
Corticosteroids & $22(78.6)$ \\
Immunosuppressive & $25(89.3)$ \\
Cyclophosphamide & $16(57.1)$ \\
Azathioprine & $16(57.1)$ \\
Cyclosporine A & $5(17.9)$ \\
Mycophenolate mofetil & $2(7.1)$ \\
Interferon alpha & $2(7.1)$ \\
Methorexate & $4(14.3)$ \\
Hydroxychloroquine & $1(3.6)$ \\
Anti-TNF alpha & $4(14.3)$ \\
Colchicine & $11(39.3)$ \\
Thalidomide & $1(3.6)$ \\
Dapsona & $1(3.6)$ \\
Fibrinolytic & $3(10.7)$ \\
Surgery & $7((25.9)$ \\
\hline
\end{tabular}

Results: The literature search resulted in 1552 articles, of which 632 were captured in Medline and 920 in Embase. Figure 1 shows the study flow-chart for article selection. The main reasons for article exclusion after full-text review were the lack venous involvement and the lack of explanation of venous involvement treatment. 28 articles reporting 1904 patients were included in qualitative analysis. The mean (range; SD) duration time between the disease onset and the vascular onset was evaluated in 15 articles and was 4.9 (1.2-9.3; 2.7) years. Superficial thrombosis was evaluated in $6(21.4 \%)$ articles, profound thrombosis in 19 $(67.9 \%)$ articles, cerebral in $7(25 \%)$, inferior or superior cava vein in $15(53.6 \%)$ and Budd-Chiari syndrome in $8(28.6 \%)$ articles. Table 1 shows the treatments described in the selected articles. Treatment response was evaluated in 20 $(71.4 \%)$ articles; in 7 of these treatments response was evaluated in a subjective way. In total, 52 (2.7\%) deaths were reported in relation to BD. In 319 (16.7\%) patients, partial efficacy or recurrence of thrombosis was reported. Considering the heterogeneity of the reported data and the variability in the measures of treatment response, predictors of mortality risk cannot be analysed. However, in the reviewed articles, a higher mortality rate was observed in in patients with hepatic involvement due to Budd-Chiari syndrome. We have also observed a higher risk for the development of venous thrombosis in patients with patergia phenomenon and male sex. Two studies suggested that immunosuppressive treatment concomitant with anticoagulant treatment is associated with a lower risk of thrombosis relapse compared with anticoagulant treatment alone.

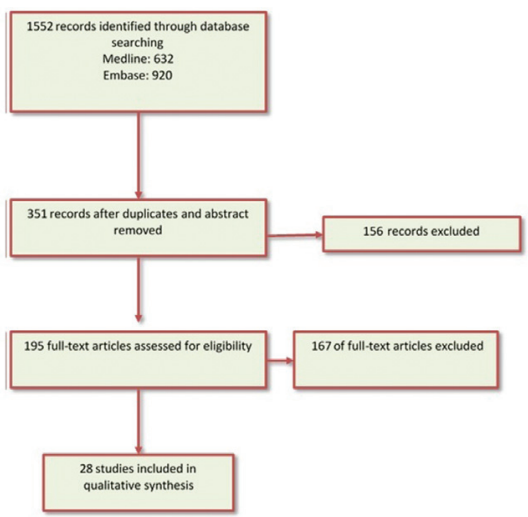

Abstract AB0668 - Figure 1

Conclusions: There is a great variability in the treatment of venous thrombosis related to Behçet's disease. Budd-Chiari syndrome seems to be related to a worse prognosis of the disease.

Disclosure of Interest: None declared

DOI: 10.1136/annrheumdis-2018-eular.5733

\section{AB0669 MAINTENANCE TREATMENT WITH ADALIMUMAB IN REFRACTORY UVEITIS DUE TO BEHÇET'S DISEASE: OPTIMISED VS NON-OPTIMISED GROUP}

J.L. Martín-Varillas ${ }^{1}$, V. Calvo-Río ${ }^{1}$, E. Beltrán ${ }^{2}$, J. Sánchez $^{3}$, M. Mesquida ${ }^{4}$, A. Adán ${ }^{4}$, M.V. Hernández ${ }^{4}$, M. Hernández ${ }^{2}$, E. Valls ${ }^{5}$, L. Martínez ${ }^{5}$, A. Sellas ${ }^{6}$, M. Cordero ${ }^{7}$, M. Díaz ${ }^{8}$, R. Gallego ${ }^{8}$, D. Salom ${ }^{9}$, N. Ortego ${ }^{10}$, J.L. García ${ }^{10}$, J. L. Callejas ${ }^{10}$, J.M. Herreras ${ }^{11}$, A.M. García ${ }^{12}$, O. Maíz ${ }^{13}$, A. Blanco ${ }^{13}$, I. Torre ${ }^{14}$, D. Díaz ${ }^{15}$, E. Pato ${ }^{15}$, E. Aurrecoechea ${ }^{16}$, M.A. Caracuel ${ }^{17}$, F. Gamero ${ }^{18}$, E. Minguez ${ }^{19}$, C. Carrasco ${ }^{20}$, A. Olive ${ }^{21}$, J. Vázquez ${ }^{22}$, O. Ruiz $^{23}$, J. Manero $^{23}$ S. Muñoz ${ }^{24}$, M. Gandía ${ }^{25}$, E. Rubio ${ }^{26}$, F.J. Toyos ${ }^{27}$, F.J. López ${ }^{28}$, J.M. Nolla ${ }^{29}$, M. Revenga ${ }^{30}$, C. González-Vela ${ }^{1}$, J. Loricera ${ }^{1}$, B. Atienza-Mateo ${ }^{1}$, R. DemetrioPablo ${ }^{1}$, J.L. Hernández ${ }^{1}$, M.A. González-Gay ${ }^{1}$, R. Blanco ${ }^{1} .{ }^{1}$ Rheumatology and Ophthalmology, HUMV, IDIVAL, Santander, ${ }^{2}$ Rheumatology and Ophthalmology $H$ Valencia, Valencia; ${ }^{3}$ Rheumatology, $H$ Valme, Sevilla; ${ }^{4}$ Rheumatology and Ophthalmology, H Clinic, Barcelona; ${ }^{5}$ Rheumatology and Ophthalmology, H Peset, Valencia; ${ }^{6}$ Rheumatology, H Vall d'Hebron, Barcelona; ${ }^{7}$ Ophthalmology, H León, León; ${ }^{8}$ Ophthalmology; ${ }^{9}$ Ophtalmology, H La Fe, Valencia; ${ }^{10}$ Autoimmune Diseases, H San Cecilio, Granada; ${ }^{11}$ Ophthalmology, $H$ Valladolid, Valladolid; ${ }^{12}$ Rheumatology, $\mathrm{H}$ Toledo, Toledo; ${ }^{13}$ Rheumatology and Ophthalmology, $\mathrm{H}$ Donosti, San Sebastián; ${ }^{14}$ Rheumatology, H Basurto, Bilbao; ${ }^{15}$ Rheumatology, $H$ San Carlos, Madrid; ${ }^{16}$ Rheumatology, H Sierrallana, Torrelavega; ${ }^{17}$ Rheumatology, H Córdoba, Córdoba; ${ }^{18}$ Rheumatology, H San Pedro Alcántara, Cáceres; ${ }^{19}$ Ophthalmology, H Zaragoza, Zaragoza; ${ }^{20}$ Rheumatology, H Mérida, Mérida;

${ }^{21}$ Rheumatology, H Germans Trias i Pujol, Badalona; ${ }^{22}$ Rheumatology, H Ferrol, A Coruña; ${ }^{23}$ Rheumatology and Ophthalmology, H Miguel Servet, Zaragoza;

${ }^{24}$ Rheumatology, H Infanta Sofía, Madrid; ${ }^{25}$ Rheumatology, H Puerta del Mar, Cádiz; ${ }^{26}$ Rheumatology, $H$ Virgen Rocío; ${ }^{27}$ Rheumatology, $H$ Virgen Macarena, Sevilla; ${ }^{28}$ Rheumatology, $H$ Gregorio Marañón, Madrid; ${ }^{29}$ Rheumatology, $H$ Bellvitge, Barcelona; ${ }^{30}$ Rheumatology, H Ramón y Cajal, Madrid, Spain

Background: Uveitis is the most common ocular manifestation in Behçet's Dis ease (BD), which can cause irreversible blindness. ${ }^{1-2}$

Objectives: To assess efficacy, safety and cost-effectiveness of adalimumab (ADA) therapy optimisation in a series of patients with uveitis due to BD.

Methods: Multicenter study of 74 ADA-treated patients with BD uveitis refractory to conventional immunosuppressants. Following remission, optimisation was performed by increasing the ADA dosing interval. Comparison between optimised and non-optimised group was performed.

Results: Ocular remission was achieved in 65 (86.6\%) patients after a median ADA duration of $6^{3-12}$ months. ADA was optimised in 23 cases. In the remaining 42 ADA was maintained at $40 \mathrm{mg} / \mathrm{sc} / 2$ weeks. No baseline differences were found at ADA onset between the optimised and non-optimised groups. Ocular outcomes were similar after a mean \pm S.D. follow-up of $34.7 \pm 13$.3 and $26 \pm 21.3$ months in the both groups (table 1). Adverse effects were seen in non-optimised group (lymphoma, pneumonia, local reaction and bacteremia). Mean ADA treatment costs were lower in the optimised vs non-optimised group (6101.25 €/ patient/year vs 12339.48). 